\title{
KNOWLEDGE OF MATHEMATICS AND PHYSICS AS BASIS FOR STUDIES IN ENGINEERING SCIENCES
}

\author{
Natalija Sergejeva, Aivars Aboltins \\ Latvia University of Life Sciences and Technologies, Latvia \\ natalija.sergejeva@1lu.lv, aivars.aboltins@1lu.lv
}

\begin{abstract}
Statistical data in recent years show stable interest in engineering sciences at higher schools in Latvia. In the present academic year, in the programs of engineering sciences and natural sciences in total about 7 thousand first year students have been enrolled, which is approximately the same as last year. At the same time, every year also large numbers of students leave the studies already in the first year. The teachers working with the first year students (including the teachers of Higher mathematics and Physics) often meet with the problem that the new students do not have equal level of preliminary knowledge. It is due to the different number of lessons in Mathematics and Physics at the secondary schools in different education programs. Qualitative engineering studies are not possible without profound preparation in mathematics. In turn, the course in Physics is like a bridge between Mathematics and Engineering science. Analysing the results of the tests of the first year LLU students, which were performed at the beginning of studies after finishing the secondary school, and the achievements of the students in the courses of Mathematics and Physics after the first semester, it was concluded that, if there is a wish to maintain the number of students in engineering sciences, there must be a repetition course in Mathematics, as well as in Physics.
\end{abstract}

Keywords: mathematics, physics, engineering education.

\section{Introduction}

In the Cambridge Academic Content Dictionary it can be found that engineering is the study of using scientific principles to design and build machines, structures, and other things, including bridges, roads, vehicles, and buildings.

Physics and mathematics are integral parts of engineering sciences. Physics teaches about the laws in the world, but mathematics helps form relations among different values. In engineering sciences the basic principles of mathematics and physics are used for solving of practical technical problems. At the same time, the practical needs of engineering technologies promote the development of physics and mathematics. Therefore, engineering technologies, physics and mathematics are closely related and they operate mutually. The role of mathematics and physics in engineering sciences should not also be considered as absolute.

As Gainsburg emphasized, ,,mathematics can be to help in many engineering situations, but it is not the only constituent of engineering work, since there are many other aspects to be taken into account, which are different from those that can be stated and treated in a mathematical way" [1]. At the same time, mathematics equips us with the skills needed to interpret and analyse information, simplify and solve problems, assess risk, make informed decisions and further understand the world around us through modelling both abstract and concrete problems [2].

As one of the main criterions "focus on learning (not on teaching)" is mentioned for education of future engineers. Here we can notice the fact that students themselves need (and can) to educate, they must find information, develop, the teacher is as an adviser, who shows where to find information, instead of presenting ready knowledge to the students. Due to this, the teacher educating future engineers should be competent also in pedagogical issues to be able to use a differentiated approach in the process of studies.

To realize the focus on learning, educators need to integrate diverse classroom (and out of classroom) techniques, like cooperative learning, active learning, visuals, etc. to address the learning styles of all students [3]. The results of student inquiries become as one of the most important factors for evaluation of the work of teachers also in the higher schools in Latvia. Nevertheless, as many researchers have stressed (let us mention, for instance, [4]), the student inquiries cannot serve as the dominating factor in evaluation of the work of teachers. The contingent, with which the teacher works, and the basis of the preliminary knowledge and skills of the students should also be taken into account. Without a strong foundation in mathematics and science from elementary and secondary school, students may find themselves unprepared to train for and pursue careers in STEM fields [5]. 
During the recent years, in Latvia stable interest of future students can be observed in engineering sciences. According to the data of the Central Statistical Bureau, within the last ten years the number of students enrolled in higher schools and colleges in the spheres of engineering sciences is about $16 \%$ of the total number of the enrolled students [6]. Fig. 1 shows the proportional number of enrolled and studying students, as well as students, who have been awarded a degree in engineering sciences, compared to the number of all enrolled and studying, and awarded a degree students, who have been enrolled in that year in total, within the last ten years.

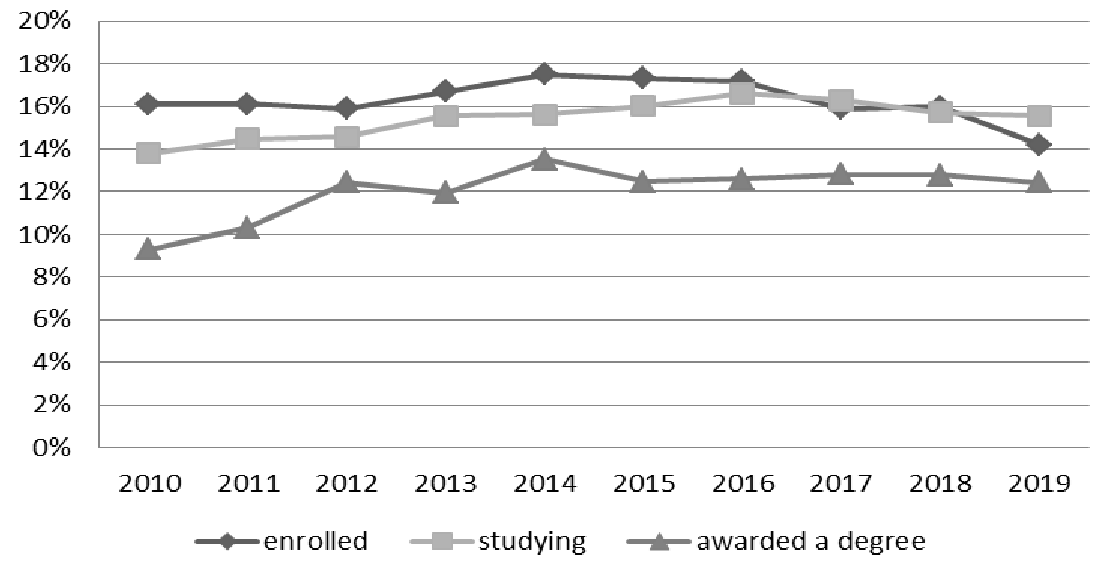

Fig. 1. Number of students in engineering sphere compared to all students at the beginning of the study year in 2010-2019

In the recent years at LLU, which is the basic work place of the authors of the article, there is a trend to reduce the number of credit points for such study courses as Higher Mathematics and Physics, planning part of them for other study courses, in which the courses of Physics and Mathematics are integrated according to the definition. This way there is an attempt to make the description of the study course more attractive to students. In the opinion of the authors of the present research, it is just vice versa; the number of credit points in Mathematics and Physics should be increased, introducing repetitive courses in these subjects to partially even up the level of student knowledge.

\section{Materials and methods}

The present research is continuation of the research performed in previous years that was described in the publications of the authors [7; 8]. But in this stage of the research, work with future engineers of a definite faculty within two years was analysed, stressing the problems for acquisition of physics and mathematics and developing some possible solutions for their elimination.

The research is based on the data of the results of students, enrolled in three study programs in the definite faculty, in physics and mathematics after finishing the secondary school and achievements at the higher school. In total in the research described in the present article, the entrance results of 72 first year students enrolled in 2018, as well as their future studies at LLU in the courses in Mathematics and Physics, were analysed. The students of the group under study were offered a course in Higher Mathematics of $10 \mathrm{CP}$ for four semesters, but a course of Physics for students of one speciality $6 \mathrm{CP}$ four two semesters, for two other groups $-4 \mathrm{CP}$. Besides, some students (students of two programs out of three) still have a basic course in Physics with $2 \mathrm{CP}$.

The obtained data were investigated in different aspects: 1) knowledge of the students in the group under study on basic issues of mathematics, entering the higher school and starting the second year of studies, was compared, 2) student performance in the courses of Mathematics and Physics was compared, 3) level of knowledge of the first year students, who had left the studies already in the first study year, was stated and some proposals to solve this problem were recommended.

In September 2018 and September 2019, starting the studies in the first and second year, the students were offered a test, which includes only mathematical basic knowledge and skills that are learned already at primary school. More detailed description of this work can be found in the authors' publication [7]. 


\section{Results and discussion}

The number of students under the specialties of study starting the first study year was 72 , starting the second year 43 , so in total $40 \%$ of the students of these three specialties have left the studies, what is not so much, if compared to the knowledge of students in physics and mathematics finishing the secondary school. With no doubt, future engineers must have high level knowledge in both of these subjects. Fig. 2 shows the proportion of all enrolled students, depending on the results in the centralised examination in mathematics. In total, the average result in the mathematics examination of all students enrolled in engineering specialties finishing school was $34.9 \%$ (we could not get information about the results in mathematics of two students). For comparison, in 2018 the average result in the examination that was compulsory for all secondary school graduates was $34.6 \%$ [9]. The data show that for $51 \%$ of the students in the group under study the results did not exceed $30 \%$, including 7 students (what is $10 \%$ of the total number) for whom it did not exceed $10 \%$. It should be mentioned at once that all these 7 students were among those, who left the studies. $17 \%$ of the enrolled students had results within $10 \%$ to $20 \%$, half of them left studies already in the first year. From the other six students, two have debts in the course of Higher Mathematics, but the others managed to pass the previous courses in Higher Mathematics in the result of several attempts. This allows to conclude that in Latvia, the same as it is, for instance, in Lithuania, the level, at which the exam is considered as passed, should be raised (at present in Latvia this level is $5 \%$, in Lithuania it is $16 \%$ ), as the data show that the students, whose school examination result is less than $20 \%$, are very seldom able to study engineering sciences.

Analysing the performance of the students who have left studies, it was found that the average results in the centralised mathematics examination at school for these students were $25.3 \%$, only for five of them the result was higher than $40 \%$.

It should be noted that for the students who continue studies the average result in the centralised mathematics examination was about $41 \% .39 \%$ of the present students had the results more than $50 \%$. These students are comparatively well prepared in mathematics and due to this they could acquire the course of Mathematics deeper, but the teachers in everyday work are forced to pay more attention to those, who have difficulties in acquiring knowledge in mathematics. In order to use the differentiated approach, in the opinion of the authors of the article, it could be possible to offer students a part of the study material in video format. As the experience shows, in the present situation because of COVID-19, the more advanced students could study independently, using consultations of teachers for discussion of complicated issues.

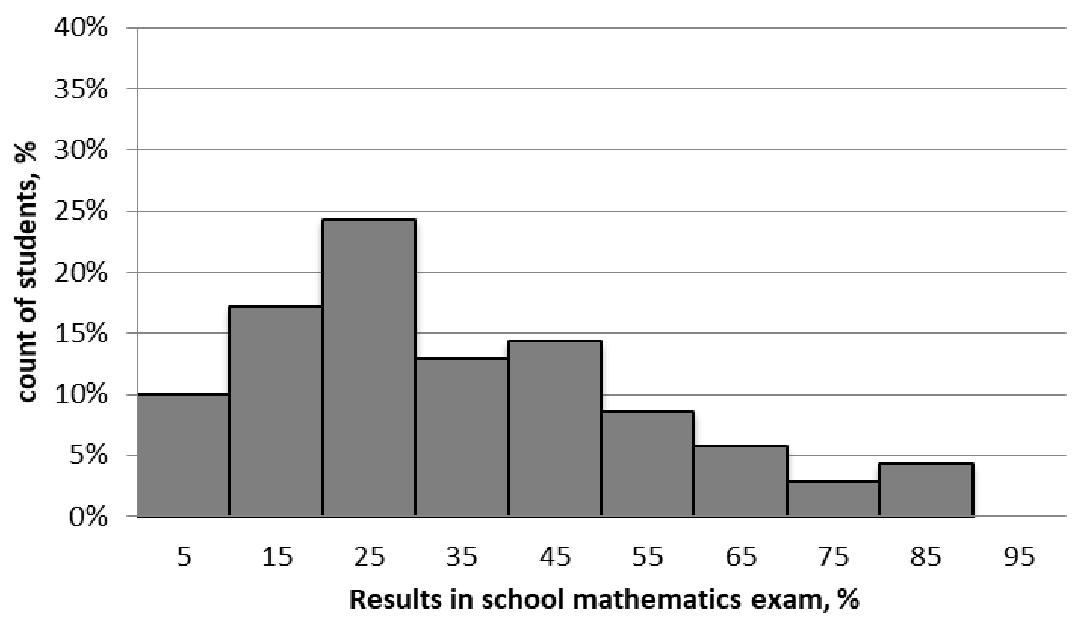

Fig. 2. Results in school centralised mathematics examination of students of the group under study

It turned out to be more difficult to analyse the results of the enrolled students in physics. The entrance regulations of LLU require that the future students of the specialties under study should have successful results in examinations in the Latvian language, foreign language and mathematics, as well as additional points are given for the result in physics in the certificate of secondary education [10]. 
Due to this, not all students indicated their cumulative grade per year, and not all of them had taken the centralised examination in physics, as this examination is not compulsory in Latvia. We should mention that the centralised examination in Latvia is considered as passed successfully, if the average number of points of its parts is at least 5 .

From the group of 72 students analysed in the research, 40 have passed the centralised physics examination. The average result for these students in total is $31.4 \%$ (for comparison, in 2018 in the country the average result in the physics examination was $39.8 \%$ ). The obtained data show (Fig. 3) that for $53 \%$ of students the result in the physics examination does not exceed $30 \%$, besides, for four students (or $10 \%$ ) it does not exceed even $20 \%$. It should be noted that similarly it was observed, investigating the number of students who have left studies, in relation to the results in the mathematics examination. These four students have left studies already in the first study year. These data prove once more that the lowest margin should be indicated for the school graduates to reach to be able to study engineering sciences at higher educational establishments later.

During the research an attempt was made to compare also the results that have been obtained in the higher school in the courses of Higher Mathematics and Physics, but such comparison can be only general, as usually for these students, who have good knowledge and skills in mathematics, also studying physics is easier. It is no use to compare numerically, as often the successful results of students are obtained in the result of several attempts.

During the research the authors tried to compare the students' grades at school in mathematics in a year with the test results, which are organised by the teachers of LLU at the beginning of studies. The correlation coefficient of this is $60.1 \%$. In turn, comparing the results of the centralised examination with the LLU test, the correlation coefficient $82.1 \%$ was obtained. So, we can conclude that the result of the centralised examination is more informative than the grade at the end of the year. It could be explained by the fact that in different schools different education programs are taught, and with this, the requirements for getting the same grade are different. It is possible to correct the tests which are performed at school, in turn, the resulting evaluation of the central examination is unified for schools of different types. It helps compare the knowledge level of future engineers in mathematics.

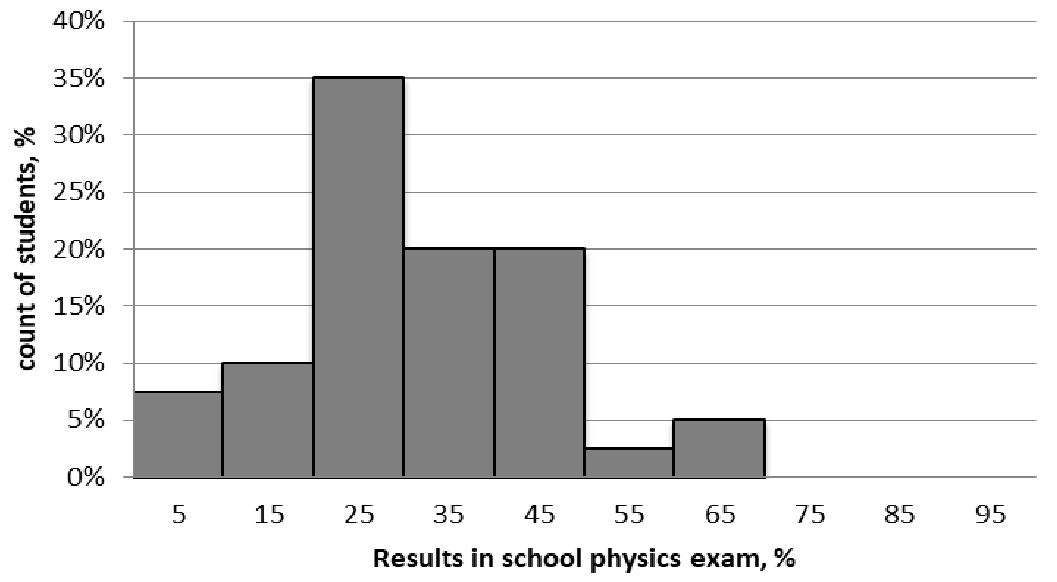

Fig. 3. Results in school centralised physics examination of students of the group under study

As it was already mentioned above, the authors of the article had a possibility to compare the students' results in mathematics, starting the studies in the first and second year, based on the same work. In both years, 41 students were tested, their performance results, as well as the grade at the central examination finishing school are shown in Fig. 4.

Starting the first study year, the average results of these students were $34 \%$, but starting studies in the second study year, it was $44 \%$. For eight students the results were lower in the second year, but this decrease is not significant (except one student, whose results had decreased approximately two times). In turn, eight students showed two or more times better results. It can be explained by their responsible attitude to the process of studies and they have contributed much work in studies. Also, the 
correlation coefficient was calculated for different test values for this group of students. In all cases the correlation is high: the correlation coefficient of both test values is $83.6 \%$, of the centralised examination and the test in the first year it is $82.6 \%$.

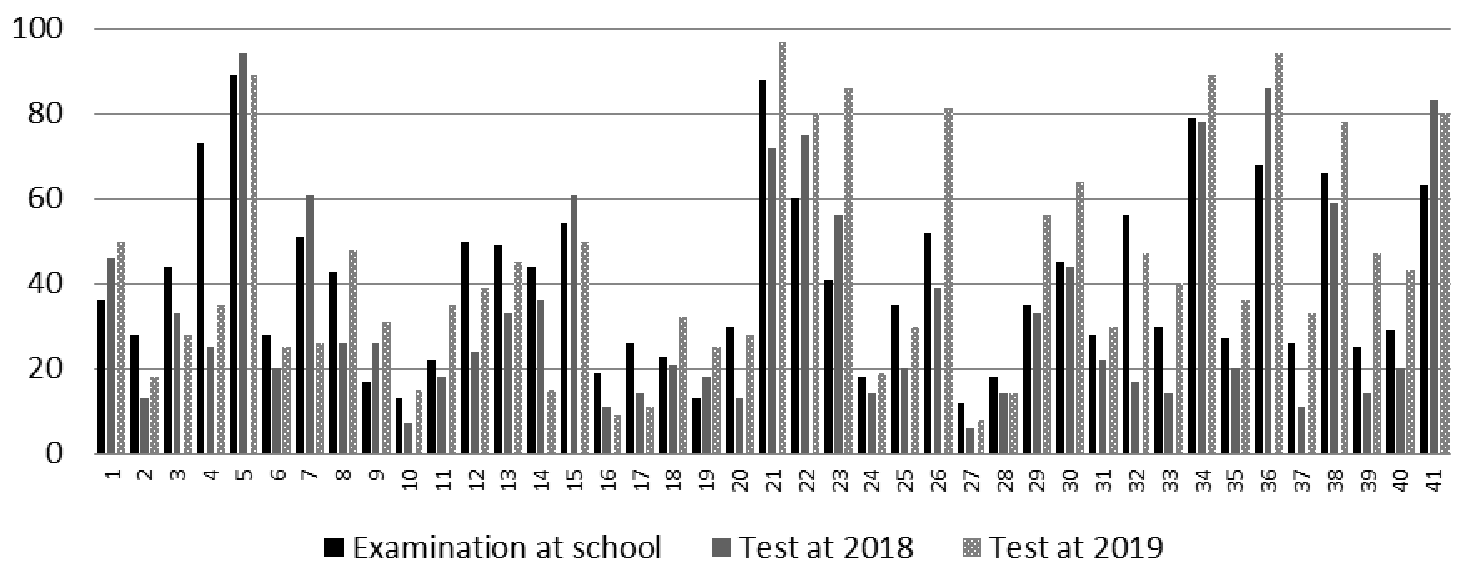

\section{Fig. 4. Comparison of results in mathematics examination finishing school} and test results in two years at university

\section{Conclusions}

1. The teacher of the course of Mathematics, who has to work with a definite group of students should have available information (it could be without names and surnames, in order to observe the data protection) about the results of students in the centralised examinations to be able to organise a repetition course operatively with the support of the Director of the program.

2. The lowest margin for entering a higher school should be determined (at least at state higher schools and colleges), as students with low preliminary knowledge in mathematics are not able to study engineering sciences, what was proved also by the results obtained in the research.

3. The number of credit points should be increased for acquisition of such fundamental sciences as mathematics and physics at Latvian higher schools. It would give wider possibilities for teachers to use the differentiated approach in the process of studies and vary the teaching methods, what is very complicated at the present number of credit points and contact hours.

\section{References}

[1] Gainsburg J. The mathematical disposition of structural engineers, Journal for Research in Mathematics Education, 38, 200, pp. 477-506.

[2] Bruton R. STEM Education Policy Statement 2017-2026, 2017. [online] [10.04.2020.] Available at: https://www.education.ie/en/The-Education-System/STEM-Education-Policy/stem-educationpolicy-statement-2017-2026-.pdf

[3] Morell L. Engineering Education in the 21st Century: Roles, Opportunities and Challenges. [online] [10.04.2020.] Available at: https://luenymorell.files.wordpress.com/2010/12/morell-engedu-in-21st-cent-roles-opport-and-challenges.pdf

[4] Boring A., Ottoboni K., Stark P.B. Student evaluations of teaching (mostly) do not measure teaching effectiveness. ScienceOpen Research, 2016. [online] [10.04.2020.] Available at: https://www.math.upenn.edu/ pemantle/active-papers/Evals/stark2016.pdf

[5] STEM Education: Preparing for the Jobs of the Future. [online] [10.04.2020.] Available at: https://www.jec.senate.gov/public/_cache/files/6aaa7e1f-9586-47be-82e7-326f47658320/stemeducation---preparing-for-the-jobs-of-the-future-.pdf

[6] Centrālā statistikas pārvalde. (Central Statistical Bureau) [online] [10.04.2020.] Available at: http://www.csb.gov.lv/ (In Latvian)

[7] Sergejeva N., Aboltins A., Strupule L., Aboltina B. Mathematical knowledge in elementary school and for future engineers. 17th International scientific conference "Engineering for rural development": Proceedings, Jelgava, Latvia, May 23-25, 2018, pp. 1166-1172. 
[8] Aboltins A., Atslega S., Sergejeva N., Strupule L. One of opportunities to reduce student dropouts. 18th International scientific conference "Engineering for rural development": Proceedings, Jelgava, Latvia, May 22-24, 2019, pp. 1941-1946.

[9] Valsts izglititibas satura centrs. (National Centre for Education of the Republic of Latvia) [online] [10.04.2020.] Available at: https://visc.gov.lv/ (In Latvian)

[10] Uzṇemšana nosacījumi Latvijas Lauksaimniecības universitātē. (Admission requirements at Latvia University of Life Sciences and Technologies) [online] [10.04.2020.] Available at: https://www.llu.lv/lv/pamatstudijas\#uznemsana (In Latvian) 